\title{
Measuring Nonvalue-Added Cost and the Cost of Excess Capacity in a Traditional Standard Cost System
}

\author{
Barbara L. Fetzer ${ }^{1} \&$ Leslie Kren ${ }^{2}$ \\ ${ }^{1}$ Department of Accounting, Marquette University, Milwaukee, Wisconsin \\ ${ }^{2}$ Lubar School of Business, University of Wisconsin-Milwaukee, Milwaukee, Wisconsin \\ Correspondence: Leslie Kren, Lubar School of Business, 3202 N. Maryland, University of Wisconsin-Milwaukee, \\ Milwaukee, WI 53201, USA Tel: 1-414-229-6075. E-mail: lkren@uwm.edu
}

Received: July 8, 2013

doi:10.5430/afr.v2n3p98
Accepted: July 22, 2013

Online Published: July 25, 2013

\begin{abstract}
While activity-based management (ABM) is typically described in the context of activity-based costing (ABC), most firms continue to use traditional standard cost systems for the majority, if not all, of their operations. The objective of this paper is to describe methods to improve cost control efforts during planning within a traditional standard cost system. Using ABM concepts for planning in a traditional standard cost system can provide the value of ABM to managers even without an underlying $\mathrm{ABC}$ system.

The intent is not to discuss benchmarking efforts but how to use benchmark data once it is available to quantify potential gains from (a) operational improvements or (b) better capacity management. These two approaches require markedly different actions from managers so explicit planning information to differentiate between the gains available from operational improvements or capacity management can be used to better direct managers' efforts.
\end{abstract}

Keywords: Activity-based management, Capacity, Standard costing, Budgeting

\section{Introduction}

\subsection{Using Activity-Based Management with a Traditional Cost System}

Traditional accounting reports showing general ledger line items provide little information to support cost control efforts during the planning process. In contrast, activity-based management (ABM) is based on the premise that spending follows from the activities that are performed in an area of responsibility so managers need to focus on activities to control spending (Cooper and Kaplan, 1992). According to ABM, as managers focus more on controlling activities, cost control efforts in the planning process can be improved (Tunney, 2010).

While activity-based management is typically described in the context of activity-based costing ( $\mathrm{ABC}$ ), most firms continue to use traditional standard cost systems for the majority, if not all, of their operations (Fry and Fiedler, 2011; Rao and Bargerstock, 2011). The objective of this paper is to describe methods to improve cost control efforts during planning within a traditional standard cost system. Thus, using ABM for planning in a traditional standard cost system can provide the value of ABM to managers even without an underlying activity-based costing (ABC) system. The discussion herein does not focus on means and methods to benchmark operations. Instead, the focus is on the use of benchmark data to explicitly quantify potential gains from operational improvements and better capacity management. Using benchmark data effectively during planning by differentiating between the gains available from operational improvements or capacity management can better direct managers' efforts.

\subsection{The Problem of Evaluating Plan Efficiency}

Planning efforts often rely on ad-hoc, subjective evaluations at the beginning of the period. For example, Meers and Robertson (2007), in a series of interviews at several successful firms, find that the planning process is informal with few standardized methodologies. Evidence in the literature, however, is clear that planning efforts that incorporate an effective framework to facilitate operational improvements can provide significant benefits for firms, including cost savings and operational efficiency (e.g., Ivert and Jonsson, 2010).

The example below demonstrates how application of ABM concepts during planning can be used to provide signals to managers to objectively evaluate plan efficiency and identify opportunities for operational improvements. Although a manufacturing example is described below, the basic cost system structure would be similar in a firm 
selling services to customers (e.g., a loan processing department at a bank) so these concepts can be as effectively applied (see, for example, Chea, 2011).

Beyond effectively evaluating planned efficiency, ABM can also be used to establish performance targets to provide understandable improvement objectives for operations managers. Such objectives may prevent some managers, when faced with cost reduction mandates, from simply throwing up their hands and making arbitrary resource cuts which can reduce firm value (Sievanen and Tomberg, 2002).

\section{Method}

\subsection{Example to Evaluate Plan Efficiency}

Consider the Fabrication Department at an OEM manufacturer. A traditional standard cost system is assumed. As often seen in production settings, the cost driver in the Fabricating Department is direct labor hours (DLH). The cost driver in any department represents the value provided to the organization and the cost driver causes department cost to be incurred.

Output for the period in the Fabrication Department is planned at 6,875 units and the standard requires 1.6 DLH per unit for a total of $11,000 \mathrm{DLH}(1.6 * 6,875)$. Total department cost for the period is planned at $\$ 282,700$, of which $\$ 121,000$ is variable with respect to the cost driver (DLH) and $\$ 161,700$ is fixed with respect to the cost driver (DLH). Given this plan, $\$ 11.00$ of variable cost is applied to each unit of output per standard DLH $(\$ 121,000 / 11,000)$ and $\$ 14.70$ of fixed cost is applied to each unit of output per standard DLH $(\$ 161,700 / 11,000)$. These calculations are summarized in table 1 .

Table 1. Fabricating Department plan cost and cost driver

\begin{tabular}{lr}
\hline plan output - units & 6,875 \\
plan DLH - 1.6 DLH per unit (standard for plan output) & 11,000 \\
variable cost (with respect to DLH) & $\$ 121,000$ \\
fixed cost (with respect to DLH) & $\$ 161,700$ \\
variable cost rate $(\$ 121,000 / 11,000)$ & $\$ 11.00$ \\
fixed cost rate at plan $(\$ 161,700 / 11,000)$ & $\$ 14.70$
\end{tabular}

Table 1 represents the accounting information from operational planning at most firms using a traditional standard cost system. Much of the data is based on careful engineering analysis and some is based on ad-hoc estimates. However, additional opportunities for efficiency gains can be uncovered by taking this plan a step further with activity-based management (ABM) concepts.

Opportunities to improve efficiency and reduce cost in the Fabricating Department arise either through (a) improvements in operational efficiency or through (b) better management of capacity (Giannetti et al, 2011). These two approaches require markedly different actions from managers so explicit planning information to differentiate between the gains available from efforts to improve operational efficiency and to manage capacity can provide value to better direct the manager's efforts. Clearly, if there is a need for better capacity management, initiatives to improve operational efficiency would be misguided. Typically, such information is not available in a traditional standard cost system. However, ABM implementation in a traditional standard cost system is possible if benchmarking is used to set productive capacity targets and identify nonvalue-added activities within responsibility areas (cost centers) in the organization (Kren, 2008).

\subsection{Estimating Value-Added Cost and Excess Capacity}

The value-added level of efficiency (i.e., benchmark) and the capacity level of output (given inputs) can be identified through studies of peer organizations and internal analyses by staff in accounting, engineering, operations, and logistics. Many firms already engage (or should engage) in benchmarking to evaluate operational efficiency and can subsequently set benchmark goals. The objective in this example is to improve the explicit information available to highlight the cost, or potential benefit, of operating below the benchmark (i.e., nonvalue-added cost), and the cost of operating below output capacity.

For the Fabricating Department, benchmark (value-added) DLH per unit of output is set at 1.4, compared to 1.6 DLH in the standard. As a result, total value-added input is 9,625 DLH $\left(1.4^{*} 6,875\right)$, compared to 11,000 DLH at standard. In addition, studies indicate that capacity input is 15,000 DLH compared to 11,000 DLH planned. Thus, 15,000 DLH 
are available but only 11,000 DLH are required to produce planned output. These calculations are summarized in table 2 .

Table 2. Fabricating Department plan, value-added, and capacity activity

\begin{tabular}{lr}
\hline plan DLH - 1.6 DLH per unit (standard for plan output) & 11,000 \\
value-added DLH for plan output - 1.4 DLH per unit & 9,625 \\
capacity DLH & 15,000 \\
\hline
\end{tabular}

The cost of excess capacity and nonvalue-added cost in the plan can now be calculated. In evaluating the cost of excess capacity, consider that the department is providing 11,000 DLH but could provide as many as 15,000 DLH with present technology. Given the level of fixed cost, the average cost per DLH would decrease if the department operated at capacity because the fixed cost would be absorbed by more output. Thus, cost could be reduced if resources could be reduced to provide only the 11,000 DLH needed rather than the 15,000 DLH available.

At this point, one might ask what is the true cost of a labor hour? As shown in table 3, variable cost per DLH would be unchanged at capacity since total VC would increase proportionately with DLH. However, fixed cost per DLH would decrease if the department operated at capacity. The cost per DLH at the plan is greater than the cost per DLH at capacity because the cost of unused resources is being allocated with resources that are used. Thus, total cost at plan includes the cost of resources used plus the cost of resources that are available but unused (to produce output). In fact, $\$ 21.78$ per DLH is the "real" cost because the cost of excess resource capacity has been removed from the cost of resources provided to users (as shown in the last line of table 3). The cost per DLH at capacity is labeled "economic" cost because it represents the cost of resources provided with current methodology if all available resources were needed by users (to produce output).

Table 3. Fabricating Department cost driver rates

\begin{tabular}{lrr}
\hline & plan & capacity \\
\hline variable cost (with respect to DLH) & $\$ 121,000$ & $\$ 165,000$ \\
fixed cost (with respect to DLH) & $\$ 161,700$ & $\$ 161,700$ \\
plan DLH - 1.6 DLH per unit (standard for plan output) & \multicolumn{2}{c}{11,000} \\
capacity DLH & \multicolumn{2}{c}{15,000} \\
variable cost rate $(\$ 121,000 / 11,000)$ & $\$ 11.00$ & $\$ 11.00$ \\
fixed cost rate at plan $(\$ 161,700 / 11,000)$ & $\underline{\$ 14.70}$ & \\
fixed cost rate at capacity $(\$ 161,700 / 15,000)$ & & $\underline{\$ 10.78}$ \\
total cost per DLH & $\underline{\underline{\$ 25.70}}$ & $\underline{\underline{\$ 21.78}}$ \\
\hline
\end{tabular}

The total cost of excess capacity is shown in table 4. Of the total 15,000 DLH available, only 11,000 are needed. Thus, $\$ 43,120$ is being spent for resources (DLH) that are not being used. The cost of resources used is calculated as the capacity (economic) cost per DLH (from table 3) multiplied by the number of DLH actually needed. Thus, if the department were the size to provide exactly the DLH needed $(11,000)$, only fixed cost would total $\$ 118,580$. Note that excess capacity is related entirely to fixed cost because variable cost changes in total with the cost driver (DLH). Table 4 indicates that the potential gains from capacity management in the Fabricating Department are $\$ 43,120$. It's important to note that improving the efficiency of work in the department by reducing the DLH needed to produce output would have no effect on excess capacity cost. Other management action is needed to reduce, or find alternate uses for, the excess capacity in the department.

Table 4. Fabricating Department excess capacity cost

\begin{tabular}{lr}
\hline resources available & $\$ 161,700$ \\
resources used - "economic" cost $(\$ 10.78 * 11,000)$ & $\underline{\$ 118,580}$ \\
excess capacity cost & $\underline{\underline{\$ 43,120}}$ \\
\hline
\end{tabular}

To calculate nonvalue-added cost, benchmark, or value-added, operating levels are used. As shown in table 2 above, the benchmark is 1.4 DLH per unit for a total of 9,625 DLH (compared to the plan of 1.6 and 11,000). For variable cost, value-added is the variable cost rate times the benchmark cost driver for a total of $\$ 105,875(\$ 11.00 * 9,625)$. Thus, value-added cost represents spending if operations were at the benchmark. Since there is no excess capacity in 
variable cost, the entire difference between value-added cost and cost incurred is nonvalue-added cost, $\$ 15,125$ $(\$ 121,000-\$ 105,875)$.

For fixed cost, value-added cost is "economic" fixed cost rate times the benchmark cost driver for a total of $\$ 103,758$

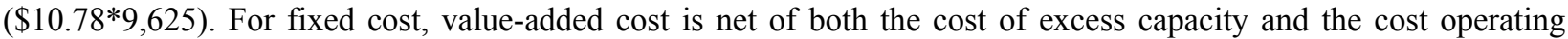
above the benchmark. Excess capacity is shown in table 4, so the nonvalue-added cost is the difference between the "economic" cost and value-added cost, \$14,822 (\$118,580-\$103,758).

Table 2 summarizes the above calculations and shows an objective evaluation of plan efficiency. The cost at capacity is denoted economic cost because the cost of unneeded labor hours is not included. The economic cost represents the lowest cost at which service can be provided, given present methodology, at the planned level of inputs, in the cost center. Value-added cost is the lowest (optimal) cost of service from the cost center if excess capacity were eliminated and inputs (i.e., DLH) were at value-added (benchmark) levels. Thus, the cost of excess capacity and the cost of nonvalue-added activity can be identified during planning, as shown in Table 2. Total plan efficiency is the difference between plan cost and value-added cost (line 3 minus line 1). That total difference can provide a measure of both excess capacity and nonvalue-added cost.

Table 5 provides two distinct measures to aid managers in cost control. First, the measure of nonvalue-added cost can provide signals to managers as they attempt to improve operational efficiency. In this effort, managers can identify specific nonvalue activities and work to reduce or eliminate them. Second, the measure of excess capacity cost can aid managers' in better management of capacity. Managers can direct their efforts toward reducing excess capacity or potentially uncover alternate uses for capacity. Since control of efficiency and management of capacity require significantly different actions from managers, gains from operational improvements can be compared to gains available from capacity management and managers can direct their efforts optimally.

Table 5. Plan efficiency in the Fabricating Department

\begin{tabular}{|c|c|c|c|c|}
\hline \multirow{2}{*}{\multicolumn{2}{|c|}{1 plan: }} & \multirow[b]{2}{*}{$\$ 11.00 * 11,000$} & Variable cost & \multirow[t]{2}{*}{ Fixed cost } \\
\hline & & & $\$ 121,000$ & \\
\hline & $\$ 1$ & $70 * 11,000$ & & $\$ 161,700$ \\
\hline \multirow[t]{2}{*}{2} & economic: $\$ 1$ & $.00 * 11,000$ & $\$ 121,000$ & \\
\hline & & $\$ 10.78 * 11,000$ & & $\$ 118,580$ \\
\hline \multirow[t]{4}{*}{3} & value-added: & $\$ 11.00 * 9,625$ & $\$ 105,875$ & \\
\hline & & $\$ 10.78 * 9,625$ & & $\$ 103,758$ \\
\hline & $(1-2)$ excess c & pacity & NA & $\$ 43,120$ \\
\hline & (2-3) nonvalu & -added & $\$ 15,125$ & $\$ 14,822$ \\
\hline
\end{tabular}

At this point, performance improvement targets based on control of excess capacity and reduction of nonvalue-added activities (and associated cost) can be assigned to responsibility area managers. Such targets provide explicit and coherent objectives for managers. For example, central management may set goals to reduce nonvalue-added activities by, say, $15.0 \%$ for the year. Operations managers could respond to performance goals by reviewing the specific activities underlying the cost drivers in their area of responsibility to determine where operational improvements are possible, resulting in future cost savings.

\section{Conclusion and Summary}

The planning process in a traditional two-stage standard cost system often relies on subjective evaluation of budget efficiency. In contrast, this example illustrates that with ABM, managers can improve their ability to differentiate between operating efficiency and capacity management during planning. The cost driver information in table 5, can be used directly by managers as they apply cost control efforts. In any traditional standard cost system, this information can be prepared for cost centers throughout the company so detailed cost control objectives is made available so every cost center manager can optimally direct his or her efforts at efficiency improvements or capacity management, as needed. Traditional standard cost center reports, show spending by accounting line items, provide modest guidance, at best, to managers as they work toward efficiency improvements.

Clearly, ABM efforts would be facilitated in an activity-based cost system (ABC) where activities have been explicitly identified, but even in the traditional standard cost system used in this example, the focus on value-added activities and excess capacity can better sustain cost management initiatives. 
Lack of system capabilities has hampered reporting of capacity information in legacy cost management systems. However, currently available ERP systems have overcome these early limitations and can routinely provide information for management of capacity and nonvalue-added cost. For example, SAP, one of the largest ERP systems, readily supports capacity planning for all cost centers in a company.

\section{References}

Chea, A.C. (2011). Activity-Based Costing System in the Service Sector: A Strategic Approach for Enhancing Managerial Decision Making and Competitiveness. International Journal of Business and Management, Vol 6, No. 11: 3. http://dx.doi.org/10.5539/ijbm.v6n11p3

Cooper, R. and Kaplan, R. (1992). Activity-Based Systems: Measuring the Costs of Resource Usage," Accounting Horizons, Vol. 6, No. 3: 1.

Fry, D.T. and Fiedler, K.D. (2011). A Tutorial on Managerial Cost Accounting: Living with Variances. Production and Inventory Management Journal. vol 47, No. 1: 21.

Giannetti, R., Venneri, C. and P. Miolo. (2011). Time-Driven Activity-Based Costing and Capacity Cost Management: The Case of a Service Firm. Cost Management. Vol 25, No 4: 6.

Ivert, L.K. and Jonsson, P. (2010). The Potential Benefits of Advanced Planning and Scheduling Systems in Sales and Operations Planning," Industrial Management \& Data Systems, Vol 110, No 5: 659.

Kren, L. (2008). Planning Internal Service Department Resources to Avoid Sub-Optimal Behavior. CPA Journal. Vol 78, No. 1: 54.

Meers, K. and Robertson, C. (2007). Strategic Planning in Profitable Small Firms in the United States," The Business Review, Cambridge, Vol 7, No. 1: 302.

Rao, M.H.S. and Bargerstock A. (2011). Exploring the Role of Standard Costing in Lean Manufacturing Enterprises: A Structuration Theory Approach", Management Accounting Quarterly, Vol 13, No. 1: 47.

Sievanen, M. and Tomberg, K. (2002). Process-Based Costing: The Best of Activity-Based Costing," AACE International Transactions, Vol 2.

Tunney, P.B.B. (2010). Activity-Based Costing: An Emerging Foundation for Performance Management. Cost Management, Vol 24, No 4: 33. 